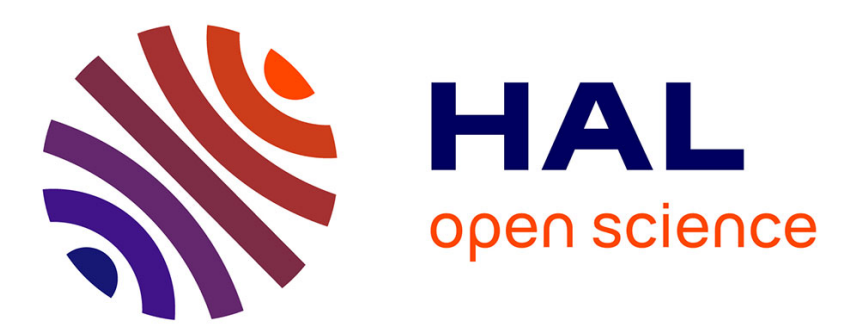

\title{
The colorimetric assay of viability for algae (CAVA): a fast and accurate technique
}

Quentin Béchet, Ivan Feurgard, Benoit Guieysse, Filipa Lopes

\section{To cite this version:}

Quentin Béchet, Ivan Feurgard, Benoit Guieysse, Filipa Lopes. The colorimetric assay of viability for algae (CAVA): a fast and accurate technique. Journal of Applied Phycology, 2015, 27 (6), pp.22892297. 10.1007/s10811-014-0508-y . hal-01096355

\section{HAL Id: hal-01096355 \\ https://hal.inria.fr/hal-01096355}

Submitted on 17 Dec 2014

HAL is a multi-disciplinary open access archive for the deposit and dissemination of scientific research documents, whether they are published or not. The documents may come from teaching and research institutions in France or abroad, or from public or private research centers.
L'archive ouverte pluridisciplinaire HAL, est destinée au dépôt et à la diffusion de documents scientifiques de niveau recherche, publiés ou non, émanant des établissements d'enseignement et de recherche français ou étrangers, des laboratoires publics ou privés.

\section{(c)(1)}

Distributed under a Creative Commons Attribution| 4.0 International License 


\section{The colorimetric assay of viability for algae (CAVA): a fast}

\section{2 and accurate technique}

3

4 Quentin Béchet $^{\mathrm{a}, \mathrm{b}}$, Ivan Feurgard ${ }^{\mathrm{a}}$, Benoit Guieysse ${ }^{\mathrm{a}, *}$, Filipa Lopes $^{\mathrm{c}}$

5 a. School of Engineering and Advanced Technology, Massey University, Private Bag 11 222,

6 Palmerston North 4442, New Zealand

7 b. INRIA BIOCORE, BP 9306902 Sophia Antipolis Cedex, France

8 c. Laboratoire de Génie de Procédés et Matériaux, École Centrale Paris, 92295 Châtenay-

9 Malabry cedex, France

10

$11 *$ Corresponding author

12 Telephone: +6463505841

13 Fax: +6463505604

14 Email: B.J.Guieysse@massey.ac.nz

15

16 
17 Abstract

18 Determining the fraction of viable cells in algal cultures is critical to improve the understanding and control of algal microbiology, ecology, and biotechnology. Whereas current techniques for algal viability determination can be rather cumbersome, this paper

21 describes a new assay that enables the rapid quantification of algal viability using only

22 spectrophotometric measurements. This technique, henceforth named CAVA test, relies on

23 the selective adsorption of erythrosine by non-viable cells and was validated on the algal 24 species Chlamydomonas reinhardtii and Chlorella vulgaris. The results obtained by the 25 CAVA test were in good agreement with the in situ measurement of oxygen production rates. 26 In addition, the CAVA test was shown to quantify the viability of algal samples regardless of 27 the cause of death (heating, UV-irradiation or $\mathrm{H}_{2} \mathrm{O}_{2}$ exposure). The CAVA technique has 28 therefore the potential to offer fast and universal approach to measure the viability of algal 29 samples.

31 Keywords: Algae; Chlorella vulgaris; Chlamydomonas reinhardtii; Erythrosine; Mortality; 32 Viability 


\section{Introduction}

The ability to rapidly and accurately quantify the ratio of viable cells over total cells within microalgal cultures, henceforth defined as 'viability', is needed in various fields of algal research (e.g. ecology, Garvey et al. 2007). For example, it is critical to determine if a certain stressor (e.g. toxicant, Gilbert et al. 1992) causes cellular death rather than, or in addition to, activity inhibition to understand the mechanisms involved. The determination of viability is therefore critical to improve the design and control of algal biotechnology as algal cells found in full-scale cultivation systems are unlikely to be $100 \%$ viable due to, typically, viral-induced death (Garza and Suttle 1998), mechanical stress (Brindley Alías et al. 2004; Gudin and Chaumont 1991), UV-irradiation (Häder et al. 1997) and rapid temperature changes (Béchet et al. 2010).

Various experimental techniques enabling the quantification of algal cells viability have been described in the literature (Markelova et al. 2000, Pouneva, 2000). The widely used 'plate cell count' consists of spreading a small volume of sample on a nutritive solid medium and counting the number of colonies formed after incubation (Allen and Smith 1966; Hwang and Horneland 1965; Madigan and Martinko 2006). The concentration of viable cells in the original sample can be determined by assuming that each visible colony originated from a single viable cell. Unfortunately, plate cell counts are often time-consuming: e.g. several days to weeks of incubation may be needed to detect colonies depending on the species studied. Alternatively, pulse amplitude magnitudes (PAM) measurements can give information on the physiological state of algal samples that can be correlated to viability in certain cases (Drábková et al. 2007). Another type of viability assessment relies on the use of dyes that stain preferentially living cells (Saga et al. 1987). For example, Fluorescein di-Acetate (FDA) 
has been highly used in previous studies to assess microalgal viability (Berglund et al. 1987; Clarke et al. 2001; Steinberg et al. 2011). Once inside the cell, esterase from the living cells cleave the FDA molecule which results in the formation of fluorescein acetate that appears bright yellow-green under fluorescent light. Various dyes selectively stain dead cells only as they penetrate the damaged cytoplasmic membranes. Examples of dyes used in prior studies include visible dyes (methylene blue; Low et al. 1994, Evans blue; Saga et al. 1987, Direct brown; Venkata Mohan et al. 2008, etc.) and, more recently, fluorescent dyes such as SYTOX Green that becomes fluorescent once in contact with DNA (Breeuwer and Abe 2000). By counting the stained cells by microscopy, the viability of the sample can be estimated. Unfortunately, while staining techniques are faster than the plate cell count, they usually involve microscope counting which is time-consuming. Cells stained by fluorescent dyes can also be counted by fluorocytometry but microbiology labs are not systematically equipped with fluorocytometers due to the high cost of this type of equipment. In order to avoid using costly equipment, Capasso et al. (2003) developed a new viability technique based on spectrophotometric measurements. The authors used 3-(4,5-dimethylthiazol-2-yl)-5-(3carboxymethoxyphenyl)-2-(4-sulfophenil)-2H-tetrazolium (referred to as 'MTS') as this dye is degraded by viable cells into a colored compound ('formazan'). The authors proved that the color development due to the formazan production was proportional to the number of viable cells. However, it is difficult to accurately estimate the fraction of viable cells with this technique because productivity may also vary with the physiological state of the viable algae (i.e. the test could underestimate true viability if viable cells under stress produce less formazan then unstressed viable cells).

This study describes the colorimetric assay of viability for algae (CAVA) which is based on the selective adsorption of erythrosine by dead algal cells and only involves 
83

spectrophotometric measurements. It has been experimentally shown that erythrosine was adsorbed by non-viable cells of 30 different algal strains (Markelova et al. 2000). Erythrosine was therefore selected as a 'staining dye' in this study. Chlamydomonas reinhardtii and Chlorella vulgaris were used as model strains representative of species broadly studied in algal biotechnology and with good potential for commercial applications (James et al. 2011; Mata et al. 2010; Spolaore et al. 2006).

\section{Materials and methods}

\subsection{Algal strain and culture conditions}

Axenic C. reinhardtii (6145C; Nelson Cawthron Institute, New Zealand) was cultivated in TAP medium (Gorman and Levine, 1969) with ammonium replaced by nitrate at the same nitrogen molar concentration. Axenic C. vulgaris (isolated in New Zealand by Landcare Research, Lincoln, New Zealand, GenBank $r b c$ L sequence: EF589154) was cultivated in sterilized BG-11 medium (Andersen et al. 2005) enriched with nitrogen $\left(0.25 \mathrm{~g} \mathrm{~N}-N O_{3}^{-} \mathrm{L}^{-1}\right)$ and $\mathrm{pH}$-buffered with phosphate salts $\left(\mathrm{KHPO}_{4}: 1.52 \mathrm{~g} \mathrm{~L}^{-1}\right.$; $\left.\mathrm{K}_{2} \mathrm{HPO}_{4}: 3.1 \mathrm{~g} \mathrm{~L}^{-1}\right)$. Following inoculation (from either solid or liquid axenic cultures) in aseptic $250 \mathrm{~mL}$ Erlenmeyer flasks, algal cultures were incubated under constant conditions of temperature $\left(25^{\circ} \mathrm{C}\right)$, agitation (orbital shaking at $160 \mathrm{rpm})$, atmospheric $\mathrm{CO}_{2}$ partial pressure $(0.5 \%)$, and illumination (14 $\mathrm{W} \mathrm{m}^{-2}$ as photosynthetically active radiation at the culture surface). Cultures in the lightlimited growth phase (linear growth) were used for the viability tests. 
105 A known volume of algae was filtered onto a pre-weighted filter (Membrane filters, $0.45 \mu \mathrm{m}$, 106 47mm, MF-Millipore ${ }^{\mathrm{TM}}$, Merck Millipore, Billerica, MA, USA). The filter was then rinsed

107 with reverse osmosis water in order to remove any salt from the filter and then dried at $105^{\circ} \mathrm{C}$

108 for one hour before being weighed. The DW concentration (expressed in the following in $g$

109 DW L ${ }^{-1}$ ) was then calculated by dividing the difference in weight by the volume of sample

110 filtered. The DW concentration was measured in duplicates.

113 Algal cells were centrifuged and re-suspended in phosphate-buffered saline solution (PBS;

$\left.1148.01 \mathrm{~g} \mathrm{~L}^{-1} \mathrm{NaCl} ; 0.20 \mathrm{~g} \mathrm{~L}^{-1} \mathrm{KCl} ; 1.60 \mathrm{~g} \mathrm{~L}^{-1} \mathrm{Na}_{2} \mathrm{HPO}_{4}, \mathrm{H}_{2} \mathrm{O} ; 0.27 \mathrm{~g} \mathrm{~L}^{-1} \mathrm{H}_{2} \mathrm{PO}_{4}\right)$. PBS was used

115 to maintain identical conditions of temperature and $\mathrm{pH}$ conditions in all the assays and did not

116 affect cell viability (data not shown). The algae were then heated at $60^{\circ} \mathrm{C}$ for $25 \mathrm{~min}$ before

117 being cooled down to $20^{\circ} \mathrm{C}$. The amount of erythrosine adsorbed on algae was found to

118 stabilize after 25 min heating (see Online Resource S1). The solution of presumably killed

119 cells was then diluted 2-fold and 4-fold to obtain a total of three algal solutions having

120 different concentrations. Each of these solutions was exposed for $10 \mathrm{~min}$ to eight erythrosine

121 concentrations (Erythrosin extra bluish, 1623-68-0 Sigma-Aldrich, USA) varying between

1220.004 to $0.12 \mathrm{~g} \mathrm{~L}^{-1}$. The amount of erythrosine adsorbed onto the biomass and the

123 concentration of free erythrosine left in solution were then determined by spectrophotometry

124 (see Section 2.4) and found to stabilize within 5 min of exposure (see Online Resource S1). In

125 the subsequent experiments, $10 \mathrm{~min}$ exposure was therefore applied in order to determine

126 sorption properties at equilibrium. 
128 The Langmuir and Freundlich isotherms were tested in order to characterize the sorption of

129 erythrosine by dead cells. Several microalgal concentrations were tested. The Langmuir

130 isotherm is described as:

$131 q=q_{m} \frac{C_{w}}{K+C_{w}}$

132 where $C_{w}$ is the erythrosine concentration in the supernatant $\left(\mathrm{g} \mathrm{L}^{-1}\right), q$ is the specific amount

133 of erythrosine adsorbed $\left(\mathrm{g} \mathrm{g} \mathrm{DW}^{-1}\right), q_{m}$ is the maximum specific amount of erythrosine

134 adsorbed by dead cells $\left(\mathrm{g} \mathrm{g} \mathrm{DW}^{-1}\right)$, and $K\left(\mathrm{~g} \mathrm{~L}^{-1}\right)$ is a saturation constant. The Freundlich

135 isotherm is described as (Gupta et al. 2006):

$136 q=K_{f}\left(C_{w}\right)^{n}$

137 where $n$, and $K_{f}\left(\mathrm{~g}^{1-\mathrm{n}}-\mathrm{L}^{\mathrm{n}} \mathrm{g} \mathrm{DW}^{-1}\right)$ are constant parameters.

140 In order to perform the CAVA test, algae were first centrifuged and re-suspended in PBS

141 (Figure 1). A first aliquot of re-suspended algal solution $(0.6 \mathrm{~mL})$ was poured in an Eppendorf

142 tube and heated for $25 \mathrm{~min}$ at $60^{\circ} \mathrm{C}$ in order to completely kill the algae. This solution was

143 then cooled down to $20^{\circ} \mathrm{C}$ by soaking the tubes in a water bath and is henceforth referred to as

144 the 'Killed sample'. A second $0.6 \mathrm{~mL}$ aliquot, henceforth referred to as the 'Sample', was

145 transferred in another Eppendorf tube and kept at $20^{\circ} \mathrm{C}$. A third $0.6 \mathrm{~mL}$ aliquot of PBS was

146 used as 'Blank'. Following the preparation of these three solutions, $0.4 \mathrm{~mL}$ of a $0.1 \mathrm{~g} \mathrm{~L}^{-1}$

147 erythrosine solution (in reverse osmosis water) at $20^{\circ} \mathrm{C}$ was added to each solution to reach an

148 initial erythrosine concentration of $0.04 \mathrm{~g} \mathrm{~L}^{-1}$. The three solutions were then maintained at

$14920^{\circ} \mathrm{C}$ for $10 \mathrm{~min}$. The tubes containing the Sample and the Killed sample were finally

150 centrifuged at $14,100 \mathrm{~g}$ for $5 \mathrm{~min}$. The erythrosine concentrations in the supernatants of the 
151 three samples were measured by spectrophotometry at $526 \mathrm{~nm}$ (the maximum peak of light

152 absorption by erythrosine solutions, determined by spectrophotometry). The optical densities

153 were measured in duplicate for the Sample and the Killed Sample and in triplicate for the

154 Blank (cuvettes: Thermo Fischer Scientific Cuvette 10x10x45mm polystyrene;

155 Spectrophotometer: Shimadzu UV-1800). Erythrosine concentration $C_{w}$ was found to be

156 proportional to the optical density at $526 \mathrm{~nm}\left(O D_{526}\right)$ according to the equation:

$157 \quad O D_{526}=\alpha C_{w}$

158 where the coefficient $\alpha$ was experimentally determined as $86.6 \mathrm{~L} \mathrm{~g}^{-1}\left(\mathrm{R}^{2}=0.9996, \mathrm{~N}=8\right)$.

2.5. Expression of the viability

161 The viability of an algal sample was determined from the optical densities of the supernatant

162 the Killed sample $\left(O D_{K}\right)$, the Sample $\left(O D_{S}\right)$, and the Blank $\left(O D_{B}\right)$. The following assumptions 163 were made:

164 1. Only dead cells adsorb erythrosine;

165 2. The sorption of erythrosine onto dead algal cells can be described by a Langmuir isotherm;

166 3. The characteristic constants of erythrosine sorption $\left(q_{m}\right.$ and $K$ in Equation 1$)$ are not

167 affected by the mechanism causing cellular death;

168 4. Erythrosine losses by degradation and volatilization are negligible.

169 The validation of Assumptions 1 to 3 is discussed thereafter in the results and discussion

170 section. Preliminary kinetic studies (Online Resource, S1) validated the Assumption 4.

172 Assuming there is no loss of erythrosine, a mass balance yields:

173

$Q_{n}=Q_{a, n}+Q_{w, n}$ 
174 where $Q_{n}(\mathrm{~g})$ is the amount of erythrosine initially added in the tube, $Q_{a, n}(\mathrm{~g})$ is the amount of

175 erythrosine adsorbed by the dead algae, $Q_{w, n}(\mathrm{~g})$ is the amount of free erythrosine remaining in 176 the solution, and $n$ stands for the solution analyzed (K - Killed sample, $\mathrm{S}-$ Sample and B-

177 Blank). As the same amount of erythrosine is initially added in each solution, $Q_{n}$ can be

178 determined as follows:

$179 Q_{K}=Q_{S}=Q_{B}=C_{w, B} V$

180 where $C_{w, B}\left(\mathrm{~g} \mathrm{~L}^{-1}\right)$ is the concentration of free Erythrosine in the Blank and $V$ is the volume of

181 the solution contained in the tube (L). Assuming that only dead cells adsorb erythrosine,

182 Equation 4 applied to the Sample and the Killed sample can be written as follows:

$Q_{a, n}+Q_{w, n}=q_{n} X_{d, n} V+C_{w, n} V$

184 where $q_{n}$ is the specific amount of erythrosine adsorbed by algae (in $\mathrm{g} \mathrm{g} \mathrm{DW}^{-1}$ ), $X_{d, n}$ the dead

185 cell concentration (in $\mathrm{g} \mathrm{DW} \mathrm{L} \mathrm{L}^{-1}$ ), $V$ the volume of the solution (L), and $C_{w, n}$ the concentration

186 of erythrosine remaining in the solution. In the case of the Killed Sample, the dead cell

187 concentration equals the total cell concentration $\left(X_{T}, \mathrm{~g} \mathrm{DW} \mathrm{\textrm {L } ^ { - 1 }}\right)$ and, assuming that

188 erythrosine sorption is described by a Langmuir isotherm, Equation 6 becomes:

$Q_{a, K}+Q_{w, K}=q_{m, H} \frac{C_{w, K}}{C_{w, K}+K_{H}} X_{T} V+C_{w, K} V$

190 When applied to the Sample, Equation 6 becomes:

191

$Q_{a, S}+Q_{w, S}=q_{m, N H} \frac{C_{w, S}}{C_{w, S}+K_{N H}} X_{d} V+C_{w, S} V$

192 where $q_{m, H}\left(q_{m, N H}\right)$ and $K_{H}\left(K_{N H}\right)$ are the maximum specific amount of erythrosine adsorbed by

193 the dead cells $\left(\mathrm{g} \mathrm{g} \mathrm{DW}^{-1}\right)$ and the Langmuir's saturation constant $\left(\mathrm{g} \mathrm{L}^{-1}\right)$ for the heated $(\mathrm{H})$

194 (and non-heated; $\mathrm{NH})$ cells, and $X_{d}$ is the dead cell concentration in the sample $\left(\mathrm{g} \mathrm{DW} \mathrm{L}^{-1}\right)$.

195 Combining Equations 3, 5, 7a, and 7b yield the two following equations: 


$$
X_{T}=\frac{1}{q_{m, H} \alpha} \frac{K_{H}{ }^{\prime}+O D_{K}}{O D_{K}}\left(O D_{B}-O D_{K}\right)
$$

$$
X_{d}=\frac{1}{q_{m, N H} \alpha} \frac{K_{N H}{ }^{\prime}+O D_{S}}{O D_{S}}\left(O D_{B}-O D_{S}\right)
$$

198 where $K_{H}$ ' and $K_{N H}$ ' are the products of $\alpha$ and $K_{H}$ and $K_{N H}$, respectively. The viability $v$ is

199 derived from the ratio of the concentration of dead cells, $X_{d}$, over the total cell concentration $200 \quad X_{T}:$

$$
v=1-\frac{X_{d}}{X_{T}}=1-\frac{q_{m, H}}{q_{m, N H}} \frac{O D_{K}}{O D_{S}} \frac{K_{N H}{ }^{\prime}+O D_{S}}{K_{H}{ }^{\prime}+O D_{K}} \frac{O D_{B}-O D_{S}}{O D_{B}-O D_{K}}
$$

Assuming the values of $q_{m}$ and $K$ are not affected by the mechanism causing cellular death

203 (Assumption 3), the viability can be expressed as follows:

204

$$
v=1-\frac{O D_{K}}{O D_{S}} \frac{K^{\prime}+O D_{S}}{K^{\prime}+O D_{K}} \frac{O D_{B}-O D_{S}}{O D_{B}-O D_{K}}
$$

205 where $K^{\prime}$ is the product of $\alpha$ and $K_{H}$ (or $K_{N H}$ assuming they are equal).

The viability of microalgae cultures exposed to different stresses and in different physiological states can be measured with this technique. In fact, comparing the quantity of erythrosine adsorbed by the Sample to the quantity of erythrosine adsorbed by the Killed Sample (Equation 10) enables accounting for the potential variations of adsorption properties of algal cells as long as Assumption 3 is verified.

\subsection{Comparison with the measurements of oxygen production rates}

213 Aliquots of killed and viable cells (from the same initial culture, the 'killed' cells being heated

214 at $60^{\circ} \mathrm{C}$ for $25 \mathrm{~min}$ and cooled down at $20^{\circ} \mathrm{C}$ ) were mixed at known volumetric ratios of 1:0;

$2153: 1 ; 2: 2 ; 1: 3$; and $0: 1$. The viability of the resulting five solutions was then assessed using the 216 CAVA test and short-term in situ oxygen productivity (in $\mathrm{mg} \mathrm{O}_{2} \mathrm{~L}^{-1} \mathrm{~s}^{-1}$ ) was measured using 
217 the device presented by Béchet et al. (2014). This device included six cylindrical vessels 218 (diameter: $49.2 \mathrm{~mm}$; height: $40 \mathrm{~mm}$ ) equipped with dissolved oxygen electrodes (Model 219 DO50-GS, Hach) and placed above LED lamps (12V PHILIPS Endura LED 10W MR16

220 Dimmable 4000K). The sides and the top lid of the vessels were opaque and the bottom wall 221 was made of a transparent polycarbonate plastic. A complete description of the device can be 222 found in Béchet et al. (2014). The five algal solutions placed in the vessels of the device were 223 exposed to the same incident light intensity $\left(63 \pm 7 \mathrm{~W} \mathrm{~m}^{-2}\right.$ as photosynthetically active radiation) and the temperature in each vessel was maintained at $22^{\circ} \mathrm{C}$. Dissolved oxygen concentration was recorded over time during the light and dark phases. The net oxygen 226 productivity and the respiration rate were obtained by linear regression. The respiration rates 227 in the dark and in the light phase were assumed to be equal. As a result, the gross rate of 228 oxygen production in each vessel was obtained by adding the rate of respiration (in absolute values) to the rate of net oxygen production as algae respire in the light phase. The CAVA test was applied to monitor changes in cell viability in algal cultures exposed to UV-irradiation or hydrogen peroxide $\left(\mathrm{H}_{2} \mathrm{O}_{2}\right)$. For UV-irradiation, an algal sample was separated in solutions of around $150 \mathrm{~mL}$ placed in four different 1L-beakers. Two beakers were irradiated by a UV lamp (Philips TUV 30W/G30 T8) placed approximately $20 \mathrm{~cm}$ above 236 the sample (UV-light intensity: $7.8 \mathrm{~W} \mathrm{~m}^{-2}$; ILT 1400 radiometer photometer equipped with a $237255 \mathrm{~nm}$ filter) while the two other beakers were protected from UV light by an opaque cover. 238 The four beakers (two sets of two replicates) were placed in an orbital shaker (agitation at 150 $239 \mathrm{rpm}$ ) to provide well-mixed conditions (no sedimentation was observed). Water evaporation 240 was compensated for by weighing the beakers and adding reverse-osmosis water every day in 
each beaker. The changes in viability in the four solutions were monitored daily. For $\mathrm{H}_{2} \mathrm{O}_{2}$

242 exposure, $\mathrm{H}_{2} \mathrm{O}_{2}(30 \%$ v/v; Code: $\mathrm{H} / 1800 / 15$, Fisher Scientific UK, Bishop Meadow Road,

243 Loughborough) was added to algal cultures (volume ratio $\mathrm{H}_{2} \mathrm{O}_{2}(30 \%)$ : algal culture of 1:4 or

$2441: 9$, see Figure 5 for details) in a closed Duran bottle continuously mixed by magnetic

245 stirring. Samples were withdrawn at regular intervals, centrifuged and re-suspended twice in

246 PBS in order to avoid any degradation of erythrosine by remaining $\mathrm{H}_{2} \mathrm{O}_{2}$. CAVA tests were

247 performed on the re-suspended solutions by following the protocol described in Section 2.4.

2.8. Monte-Carlo simulations for uncertainty estimation

250 Uncertainty on viability measurements was introduced by experimental error on the optical

251 densities measurement $\left(O D_{S}, O D_{K}\right.$ and $O D_{B}$ in Equation 10). A statistical analysis on

252 duplicate measurements revealed that the error on optical density was normally distributed

253 (see Online Resource S2 for details). Monte-Carlo simulations were then used in order to

254 determine how the error on experimental measurements impacted the accuracy of the viability

255 estimations as described in Online Resource S2.

3.1. Characterization of the adsorption isotherm

259 Erythrosine absorption onto biological tissues has been shown to be characterized by both the

260 Langmuir and the Freundlich isotherm for hen feathers (Gupta et al. 2006), de-oiled mustard

261 (Jain and Sikarwar 2009), or de-oiled soya (Mittal et al. 2006). However, and to the best of

262 our knowledge, the adsorption of erythrosine by dead algal cells has never been characterized

263 and is the object of this first section. 
265 According to Figure 2, the Freundlich isotherm could not represent erythrosine adsorption 266 onto killed $C$. reinhardtii cells. On the other hand, both Langmuir and Freundlich isotherms 267 could describe the experimental data collected for $C$. vulgaris (Figure 2). The Langmuir 268 isotherm was shown to describe the sorption equilibrium over a large range of algal 269 concentrations (0.24-0.96 $\mathrm{g} \mathrm{DW} \mathrm{L}^{-1}$ for $C$. reinhardtii and $0.43-1.7 \mathrm{~g} \mathrm{DW} \mathrm{L}^{-1}$ for $C$. vulgaris) 270 and erythrosine concentrations (0.01-0.12 $\left.\mathrm{g} \mathrm{L}^{-1}\right)$. In addition, the parameters of the Langmuir 271 isotherm, $q_{m}$ and $K$, (Equation 1) did not significantly change with the algal concentrations as 272 shown by the confidence intervals in Table 1. Langmuir's behavior was also observed when 273 C. vulgaris cells were killed by exposure to hydrogen peroxide instead of heating (data not 274 shown). High temperature is known to kill cells by protein denaturation and hydrogen 275 peroxide is a strong oxidizer, affecting, for instance, enzymes in the Calvin Cycle (Drábková et al. 2007; Takeda et al. 1998). These results validate Assumption 2 (see Section 2.5) and the Langmuir model was subsequently used as the basis for calculating viability. In Sections 3.2 to 3.4, the half-saturation constants of the Langmuir isotherm (and the associated confidence 279 interval) were taken equal to the values resulting from the fitting of the experimental points 280 obtained for the three algal concentrations (values in bold in Table 1). The Langmuir isotherm 281 suggests the binding of erythrosine as a monolayer. Differences in the cell wall biochemistry 282 of the two algal species studied likely explain the difference of $q_{m}$ values found between these 283 species (Table 1). Almost no erythrosine was adsorbed by non-killed cells, suggesting that the 284 adsorption of erythrosine onto dead cells is likely associated with a loss of cell wall integrity 285 causing binding onto otherwise unavailable intracellular material (Markelova et al. 2000). 
In order to benchmark the CAVA test against other viability assays, oxygen productivity and colorimetric viability were measured in partly killed algal cultures. As can be seen in Figure 3, oxygen productivity was close to linearly correlated to the measured viability in algal samples containing different fractions of dead and viable cells, the uncertainty being mostly caused by experimental error. Because oxygen production by algae is the result of photosynthesis and cannot be performed by dead cells, the good agreement between the CAVA results and oxygen productivities indirectly indicates that living cells do not adsorb erythrosine, thus validating Assumption 1 (see Section 2.5). A slight limitation of the technique is the fact that the measured viability in the Killed sample was estimated to be close to $10-15 \%$ (Figure 3). This limitation is further discussed in Section 3.4. Figures 4 and 5 show that the measured viability of cultures exposed to $\mathrm{H}_{2} \mathrm{O}_{2}$ and UV light decreased over time, as expected. The decrease of viability in the cultures exposed to UV light was not due to natural death as the viability of the algal sample not exposed to UV light remained constant over the duration of the experiment (Figure 4). In addition, the CAVA tests showed that the rate of cellular death seemed to increase, as expected, with the $\mathrm{H}_{2} \mathrm{O}_{2}$ concentration for C. reinhardtii (Figure 5). The expected decrease in viability observed when cells are exposure to UV light or hydrogen peroxide suggests that the CAVA test is able to monitor the viability of algal samples killed by different techniques. This result is important 308 as heating, $\mathrm{H}_{2} \mathrm{O}_{2}$ and UV light cause death through different mechanisms: heating denatures 309 proteins; $\mathrm{H}_{2} \mathrm{O}_{2}$ is a strong oxidizer, and UV light damages DNA. In spite of these differences, the CAVA test yielded trends that were consistent with expected results. 
313 Erythrosine concentration can be optimized to maximize the precision of the CAVA test. The

314 accuracy of the measured viability depends on the amount of erythrosine adsorbed by algae.

315 This quantity is obtained by the difference between the amount of erythrosine initially

316 introduced and the amount remaining the supernatant. As a result, the greater the amount of

317 erythrosine adsorbed, the higher the accuracy. It is therefore recommended to use

318 concentrated algal samples (e.g. $>1 \mathrm{~g} / \mathrm{L}$ ) to maximize the amount of erythrosine adsorbed by

319 dead cells when using this assay. For example, in a hypothetical case of a $50 \%$-viable sample

320 of $C$. vulgaris, the confidence interval on the measured viability can decrease from $\pm 20 \%$ to

$321 \pm 6 \%$ when the algal concentration increases from 0.5 to $2 \mathrm{~g} \mathrm{DW} \mathrm{L}^{-1}$ (see Online Resource S3

322 for details). Measuring the optical densities $O D_{S}$ and $O D_{K}$ in triplicates should reduce

323 uncertainty further.

325 A limitation of the CAVA test is that the measured viability of cultures exposed to $\mathrm{H}_{2} \mathrm{O}_{2}$ did 326 not reach exactly $0 \%$ but stabilized at values close to $10 \%$ for $C$. reinhardtii and $15 \%$ for $C$.

327 vulgaris (Figure 5). These plateau values were reproducible, as shown in Figure 5, and

328 therefore unlikely caused by experimental error. However, this overestimation of viability

329 was not observed when algae were killed by UV-exposure. Microalgae exposure to $\mathrm{H}_{2} \mathrm{O}_{2}$ may

330 change adsorption properties of the cells (i.e. values of $K$ or $q_{m}$ ), affecting the viability

331 calculation. As mathematically demonstrated in the Online Resource S4, the variability of $K$

332 (due to physiological changes) does not significantly increase the uncertainty of the estimated

333 viability. However, the value of the coefficient $q_{m}$ may differ between the Sample and the

334 Killed sample due to different combinations of stressors involved (e.g. the combined action of 
$\mathrm{H}_{2} \mathrm{O}_{2}$ exposure and heating in the Killed sample versus $\mathrm{H}_{2} \mathrm{O}_{2}$ exposure only for the Sample).

336 Such difference could explain the 10-15\% overestimation of viability seen in Fig. 5. This explanation is consistent with the observations of Imase et al. (2013) who showed that $\mathrm{H}_{2} \mathrm{O}_{2}$ may affect Chlorella sorokiniana by creating tiny holes in the cell membranes. This possible change of adsorption properties in the presence of $\mathrm{H}_{2} \mathrm{O}_{2}$ challenges Assumption 3. In order to improve the method for viability determination when microalgae are subjected to hydrogen peroxide stress, further assays should be performed to characterize erythrosine adsorption on those cells.

Even if this study was limited to two algal species, erythrosine was shown to be adsorbed by more than 30 algal species including cyanobacteria by Markelova et al. (2000), suggesting that the CAVA test can potentially be applied to an important variety of algal species. In addition, the same protocol can theoretically be applied to different dyes such as Methylene blue (Low et al. 1994), Evans blue (Saga et al. 1987), or Direct brown (Venkata Mohan et al. 2008) which were shown to be adsorbed by dead algal cells. The technique is also relatively fast compared to other viability assays and is also practical as no microscopic observation is required. For example, the dual fluorescence assay proposed by Sato et al. (2004) and Shulze et al. (2011) using SYTOX Green and auto-fluorescence requires microscopy counting to distinguish living cells (appearing red) from dead cells (appearing green). Counting could be easily performed using a fluorocytometer but this type of equipment is expensive. In contrast, the CAVA test only requires a common and affordable spectrophotometer. To the best of our knowledge, the CAVA test is the first spectrophotometric viability assay that enables the direct quantification of the fractions of living and dead cells. The viability method presented in this study has therefore the potential to offer a fast and universal approach to measure the viability of algal samples. Among its possible applications, the CAVA test may be used to 
evaluate microalgal viability in outdoor cultivation systems where cells undergo stresses such

361 as high temperature and UV-irradiation.

\section{Conclusions}

364 First, erythrosine adsorption onto dead $C$. vulgaris and $C$. reinhardtii cells could be described

365 by the Langmuir isotherm. By applying the CAVA technique on partially killed samples

366 containing both living and dead algal cells, the CAVA results were in good agreement with

367 in-situ measurements of oxygen productivity. In addition, the CAVA test could quantify cells

368 viability over time in algal cultures subjected to diverse mechanisms causing cellular death

369 (heating, UV-irradiance, exposure to $\mathrm{H}_{2} \mathrm{O}_{2}$ ) for the two algal species studied. Finally, the

370 CAVA test can hypothetically be applied to any dye exclusively adsorbed by dead algal cells.

371 The technique has therefore the potential to offer a fast, practical and universal approach to

372 measure the viability of algal samples.

374 5. Acknowledgments

375 Dr. Mike Packer, Cawthron institute (New Zealand), is kindly acknowledged for providing

376 axenic cultures of $C$. reinhardtii. Cyril Breton, Ecole Centrale Paris (France), and Laura

377 Etienne, Massey University (New Zealand) are also acknowledged for preliminary

378 experimental work during the technique development. Maxence Plouviez, Massey University

379 (New Zealand) is also thanked for his help all along the project. 
References

381 Allen MM, Smith AJ (1969) Nitrogen Chlorosis in blue-green algae. Arch Mikrobiol 69:114382 120.

383 Andersen RA, Berges JA, Harisson PJ, Watanabe MM (2005) Appendix A-Recipes for 384 freshwater and seawater media. In: Andersen, RA. Algal Culturing Techniques. Singapore: 385 Elsevier Academic press. pp 429-530.

386 Béchet Q, Chambonnière P, Shilton A, Guizard G, Guieysse B (2014) Algal productivity 387 modeling: a step toward accurate assessments of full-scale algal cultivation. (submitted) 388 Béchet Q, Shilton A, Fringer O, Munoz R, Guieysse B (2010). Mechanistic modelling of 389 broth temperature in outdoor photobioreactors. Environ Sci Technol 44:2197-2203.

390 Berglund DL, Taffs RE, Robertson NP (1987) A rapid analytical technique for flow 391 cytometryic analysis of cell vibility using Calcofluor White M2R. Cytometry 8:421-426. 392 Breeuwer P, Abee T (2000) Assessment of viability of microorganisms employing 393 fluorescence techniques. International J Food Microbol 55:193:200.

394 Brindley Alías C, García-Malea López, Acién Fernández, Fernández Sevilla JM, García 395 Sánchez JL, Molina Grima E (2004) Influence of Power supply in the feasibility of 396 Phaeodactylum tricornutum cultures. Biotechnol Bioengineer 87:723-733.

397 Clarke JM, Gillings MR, Altavilla N, Beattie AJ (2001) Potential problems with fluorescein 398 diacetate assays of cell viability when testing natural products for antimicrobial activity. J 399 Biol Methods 46:261-267.

400 Dismukes GC, Carrieri D, Bennette N, Ananyev GM, Posewitz MC (2008) Aquatic 401 phototrophs: efficient alternatives to land-based crops for biofuels. Curr Opin Biotechnol 402 19:235-240. 
Garvey M, Moriceau B, Passow U (2007) Applicability of the FDA assay to determine the 404 viability of marine phytoplankton under different environmental conditions. Mar Ecol Prog 405 Ser 352:17-26.

406 Garza DR, Suttle CA (1998). The effect of cyanophages on the mortality of Synechococcus 407 spp. and selection for UV resistant viral communities. Microb Ecol 36:281-292.

408 Gilbert F, Galgani F, Cadiou Y (1992) Rapid assessment of metabolic activity in marine 409 microalgae: application in ecotoxicological tests and evaluation of water quality. Mar Biol $410 \quad 112: 199-205$.

411 Gorman DS, Levine RP (1965) Cytochrome f and plastocyanin: their sequence in the 412 photosynthetic electron transport chain of Chlamydomonas reinhardi. Proc Natl Acad Sci 413 USA 54(6):1665-1669.

414 Gudin C, Chaumont D (1991) Cell fragility - the key problem of microalgae mass production 415 in closed photobioreactors. Biores Technol 38:145-151.

416 Gupta VK, Mittal A, Kurup L, Mittal J (2006) Adsorption of a hazardous dye, erythrosine, 417 over hen feathers. J Colloid Interface Sci. 304:52-57.

418 Häder DP, Kumar HD, Smith RC, Worrest RC (2007) Effects of solar UV radiation on 419 aquatic ecosystems and interactions with climate change. Photochem Photobiol Sci 6:267420285.

421 Hwang SW, Horneland W (1965) Survival of algal cultures after freezing by controlled and 422 uncontrolled cooling. Cryobiol 1(5): 305-311.

423 Imase M, Ohko Y, Takeuchi M, Hanada S (2013) Estimating the viability of Chlorella 424 exposed to oxidative stresses based around photocatalysis. Int Biodeter Biodegr 78:1-6. 425 Jain R, Sikarwar S (2009) Adsorptive removal of Erythrosine dye onto activated low cost de426 oiled mustard. J Hazard Mater 164:627-633. 
James GO, Hocart CH, Hillier W, Chen H, Kordbacheh F, Price GD, Djordjevic MA (2011).

428 Fatty acid profiling of Chlamydomonas reinhardtii under nitrogen deprivation. Biores

429 Technol 102:3343-3351.

430 Leite GB, Abdelaziz AEM, Hallenbeck PC (2013) Algal biofuels: challenges and

431 opportunities. Biores Technol 145:134-141.

432 Low KS, Lee CK, Toh BL (1994) Binding of Basic Dyes by the Algae, Chara aspera.

433 Pertanika J Sci Technol 2(1):85-92.

434 Madigan MT, Martinko JM (2006) Brock - Biology of microorganisms. 11th Edition.

435 Pearson Prentice Hall. Upper Saddle River, NJ 07458.

436 Markelova AG, Vladimirova MG, Kuptsova ES (2000) A comparison of cittochemical 437 methods for the rapid evaluation of microalgal viability. Russ J Plant Physiol 47:815-819.

438 Mata TM, Martins AA, Caetano NS (2010) Microalgae for biodiesel production and other 439 applications: a review. Renew Sustain Energy Rev 14:217-232.

440 Mittal A, Mittal J, Kurup L, Singh AK (2006). Process development for the removal and 441 recovery of hazardous dye erythrosine from wastewater by waste materials - Bottom Ash and 442 De-Oiled Soya as adsorbents. J Hazard Mater B138:95-105.

443 Pouneva I (1997). Evaluation of algal culture viability and physiological state by fluorescent 444 microscopic methods. Bulg J Plant Physiol 23(1-2):67-76.

445 Saga N, Machiguchi Y, Sanbonsuga Y (1987). Application of staining for determining 446 viability of cultured algal cells. Bull Hokkaido Reg Fish Res Lab 51:39-44.

447 Schulze K, López DA, Tillich UM, Frohme M. 2011. A simple viability analysis for 448 unicellular cyanobacteria using a new autofluorescence assay, automated microscopy, and 449 ImageJ. BMC Biotechnol 11:118.

450 Spolaore P, Joannis-Cassan C, Duran E, Isambert A (2006). Commercial applications of 451 microalgae. J Biosci Bioeng 101(2):87-96. 
452 Steinberg MK, Lemieux EJ, Drake LA (2011). Determining the viability of marine protists 453 using a combination of vital, fluorescent stains. Mar Biol 158: 1431-1437.

454 Venkata Mohan, S, Ramanaiah, SV, Sarma, PN (2008). Biosorption of direct azo dye from 455 aqueous phase onto Spirogyra sp. I02: Evaluation of kinetics and mechanistic aspects. 456 Biochem Eng J 38:61-69.

457 Walker DA (2009). Biofuels, facts, fantasy, and feasibility. J Appl Phycol 21: 509-517. 458 
Figures

460

461 Fig. 1 Schematic description of the protocol of the colorimetric assay of viability for algae

Fig. 2 Amount of erythrosine adsorbed by dead algal cells for different erythrosine concentrations in the supernatant at equilibrium. Algal concentrations (C. reinhardtii/C. vulgaris in $\mathrm{D} \mathrm{DW} \mathrm{L}^{-1}$ : red circles: 1.7/0.96; blue diamonds: $0.85 / 0.48$; black crosses: 0.43/0.24). Plain line: fitting with a Langmuir isotherm; dashed-line: fitting with a Freundlich isotherm. Values of fitted parameters are given in Table 1. Error bars represent 95\% confidence intervals calculated using Monte-Carlo simulations

Fig. 3 Comparison between the oxygen productivity and the measured viability of algal samples partly killed by heating (a: C. reinhardtii, $0.32 \mathrm{~g} \mathrm{DW} \mathrm{L}^{-1}$; b: C. vulgaris, $0.32 \mathrm{~g}$ DW

$\left.\mathrm{L}^{-1}\right)$. The oxygen productivity was normalized to the oxygen productivity in the sample

474 containing only non-killed cells. The error bars represent the $95 \%$ confidence intervals

475 estimated using Monte-Carlo simulations

477 Fig. 4 Viability of cultures exposed to UV light over time. Algal concentrations: $C$.

478 reinhardtii: $0.57 \mathrm{~g} \mathrm{DW} \mathrm{L}^{-1} ;$ C. vulgaris: $0.69 \mathrm{~g} \mathrm{DW} \mathrm{L}^{-1}$. The error bars represent $95 \%$

479 confidence intervals calculated through Monte-Carlo simulations

481 Fig. 5 Viability of cultures exposed to hydrogen peroxide. $\mathrm{H}_{2} \mathrm{O}_{2}$ concentration/algal 482 concentration: $C$. reinhardtii: white: $6 \% / 0.78 \mathrm{~g} \mathrm{DW} \mathrm{L}^{-1}$; grey: $3 \% / 0.88 \mathrm{~g} \mathrm{DW} \mathrm{L}^{-1}$; $C$. 
483 vulgaris: white: $6 \%$ / $1.3 \mathrm{~g} \mathrm{DW} \mathrm{L}^{-1}$; grey: $6 \% / 0.48 \mathrm{~g} \mathrm{DW} \mathrm{L}^{-1}$. The error bars represent the $48495 \%$ confidence interval calculated through Monte-Carlo simulations 
Table 1: Langmuir and Freundlich isotherms parameters for C. reinhardtii and C. vulgaris ( $X$ : algal concentration in $\mathrm{g}$ DW/L; units: $\left.q_{m}: \mathrm{mg} / \mathrm{g} ; K: \mathrm{mg} / \mathrm{L} ; K_{f}: 10^{-3} \mathrm{~g}^{1-\mathrm{n}}-\mathrm{L}^{\mathrm{n}} / \mathrm{g}^{\mathrm{n}} ; n:-\right) .95 \%$ confidence intervals calculated using Monte-Carlo simulations are shown in parenthesis. Values in bold characters result from the fitting of data from all algal concentrations.

\begin{tabular}{|c|c|c|c|c|c|c|c|c|c|}
\hline \multirow{2}{*}{ Algae } & \multirow{2}{*}{$X$} & \multicolumn{4}{|c|}{ Langmuir isotherm } & \multicolumn{4}{|c|}{ Freundlich isotherm } \\
\hline & & $q_{m}$ & $K$ & $q_{m}$ & $\boldsymbol{K}$ & $K_{f}$ & $n$ & $\boldsymbol{K}_{f}$ & $n$ \\
\hline \multirow{6}{*}{$\begin{array}{c}C . \\
\text { reinhardtii }\end{array}$} & 006 & 84.6 & 21.4 & \multirow{6}{*}{$\begin{array}{l}86.4 \\
(4.1)\end{array}$} & \multirow{6}{*}{$\begin{array}{l}25.0 \\
(3.1)\end{array}$} & 418 & 0.623 & \multirow{6}{*}{$\begin{array}{c}366 \\
(121)\end{array}$} & \multirow{6}{*}{$\begin{array}{c}0.614 \\
(0.090)\end{array}$} \\
\hline & 0.90 & $(2.9)$ & $(2.0)$ & & & $(170)$ & $(0.114)$ & & \\
\hline & 0.48 & 91.4 & 27.2 & & & 403 & 0.632 & & \\
\hline & 0.48 & $(5.0)$ & $(4.0)$ & & & $(231)$ & $(0.128)$ & & \\
\hline & \multirow{2}{*}{0.24} & 86.3 & 29.0 & & & 387 & 0.626 & & \\
\hline & & $(10.2)$ & $(9.2)$ & & & $(754)$ & $(0.243)$ & & \\
\hline \multirow{6}{*}{ C. vulgaris } & 17 & 17.8 & 25.3 & \multirow{6}{*}{$\begin{array}{l}22.4 \\
(4.7)\end{array}$} & \multirow{6}{*}{$\begin{array}{c}37.8 \\
(15.8)\end{array}$} & 53.6 & 0.516 & \multirow{6}{*}{$\begin{array}{c}58.6 \\
(21.7)\end{array}$} & \multirow{6}{*}{$\begin{array}{c}0.529 \\
(0.103)\end{array}$} \\
\hline & 1.1 & $(2.2)$ & (7.1) & & & $(16.2)$ & $(0.087)$ & & \\
\hline & & 25.1 & 44.9 & & & 64.8 & 0.540 & & \\
\hline & 0.85 & $(6.9)$ & $(24.2)$ & & & $(40.5)$ & $(0.151)$ & & \\
\hline & & 25.7 & 48.7 & & & 70.8 & 0.532 & & \\
\hline & 0.43 & (76.5) & $(364)$ & & & $(681.4)$ & $(0.292)$ & & \\
\hline
\end{tabular}




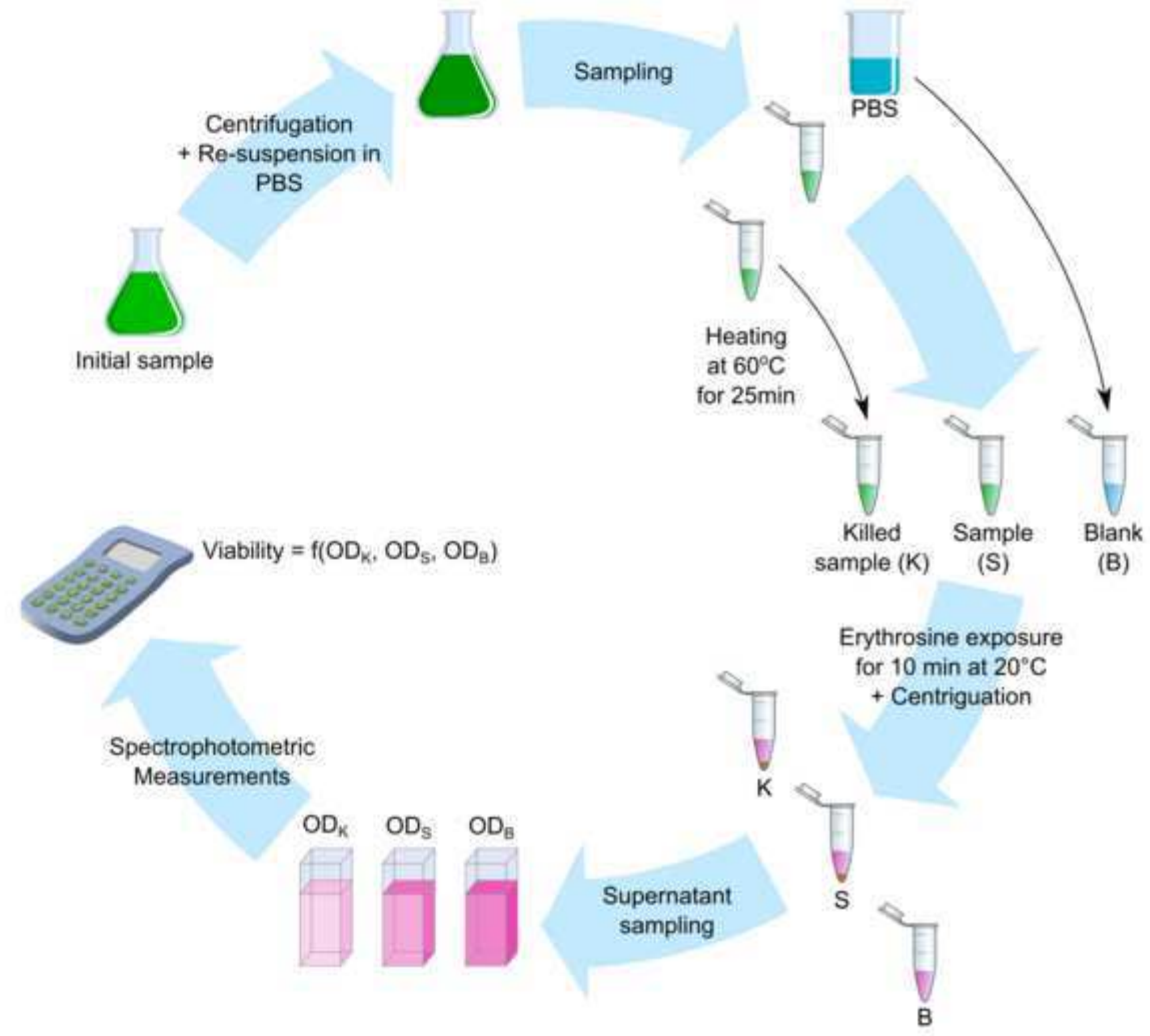



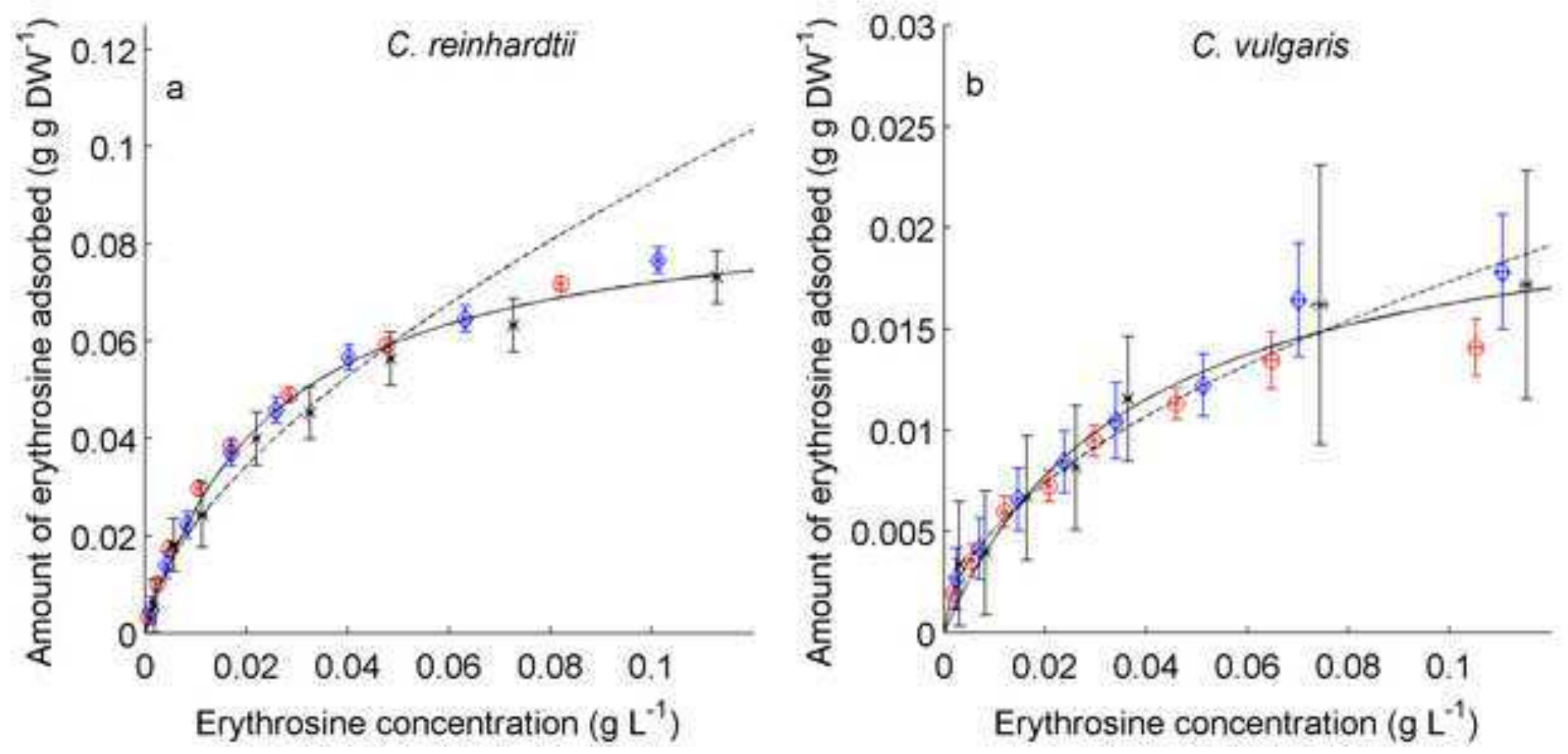

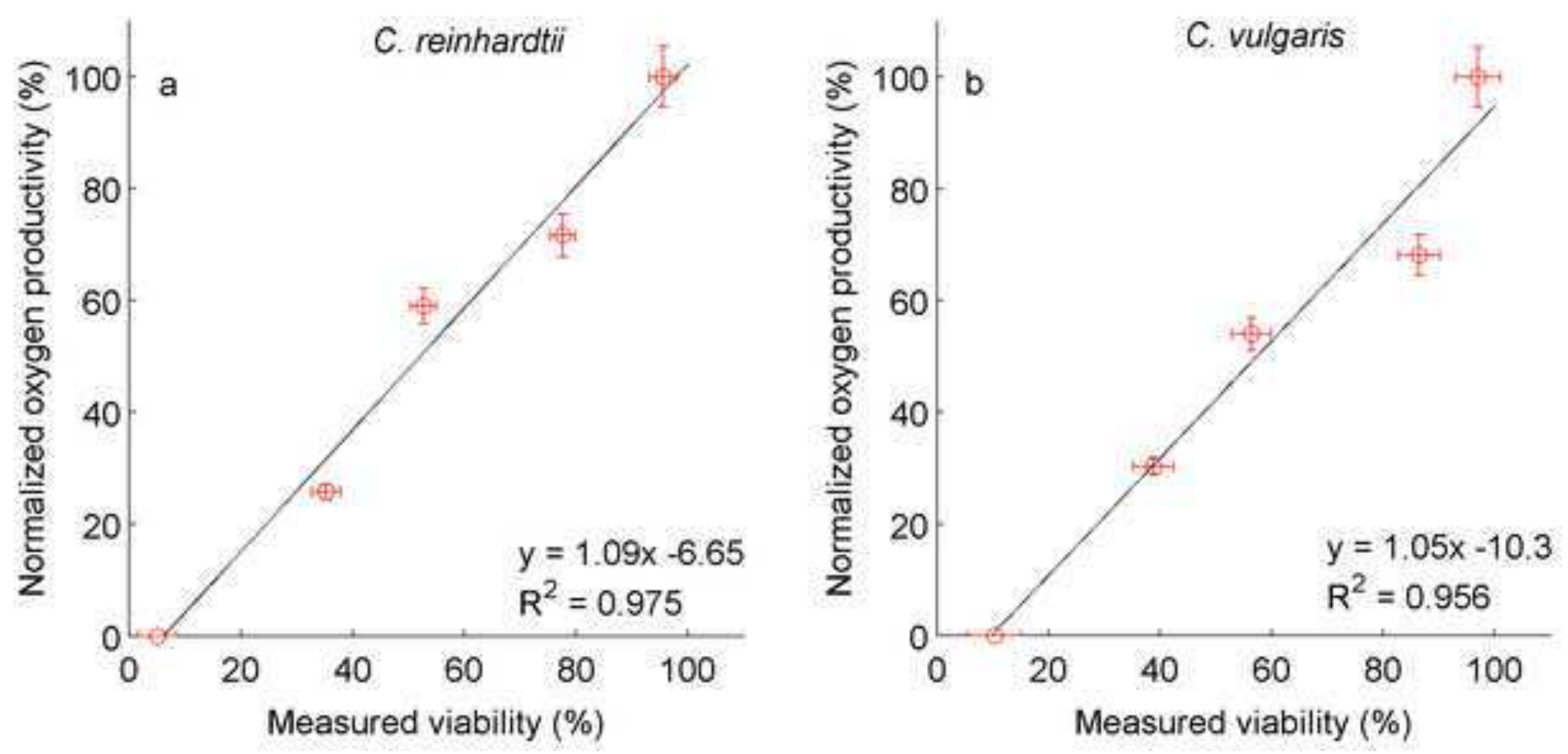


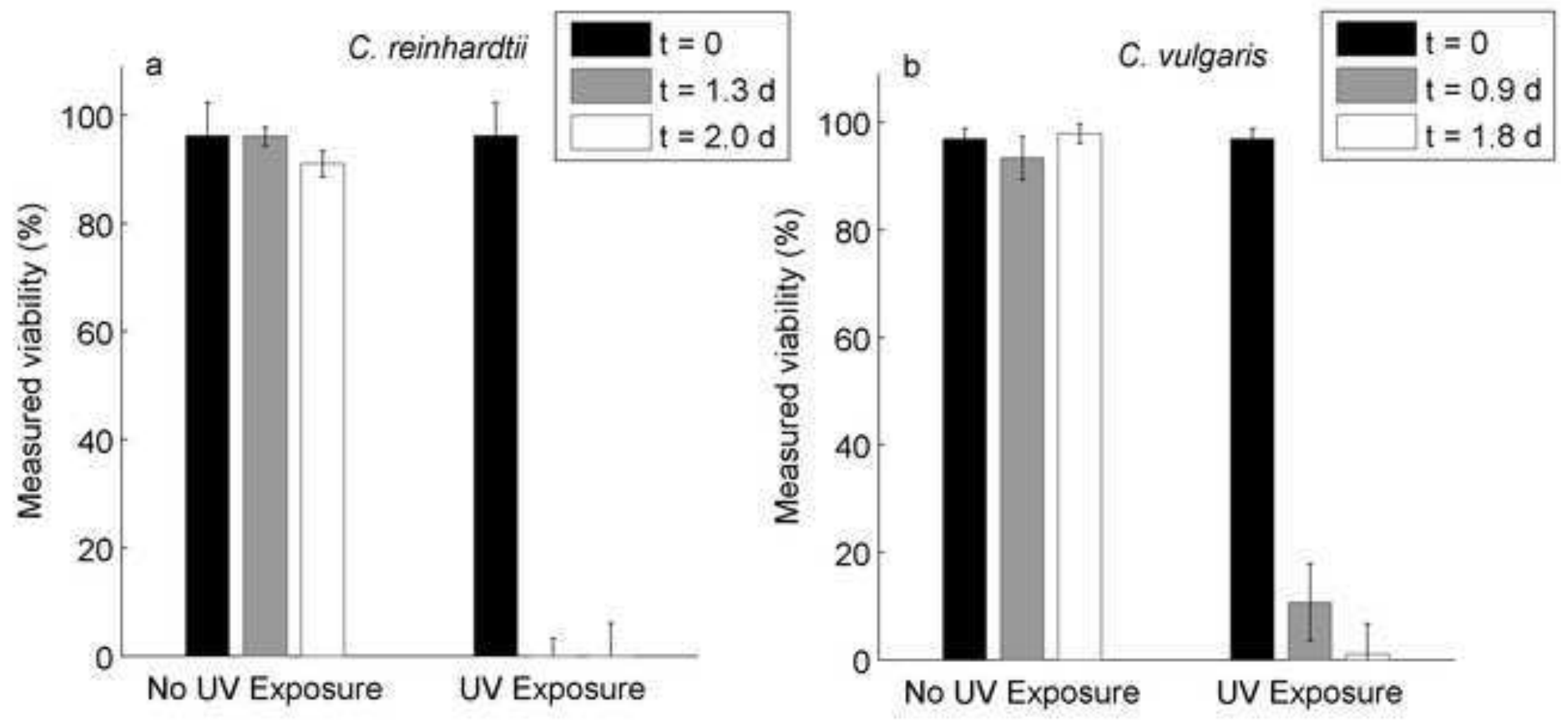


Figure 5
Click here to download high resolution image
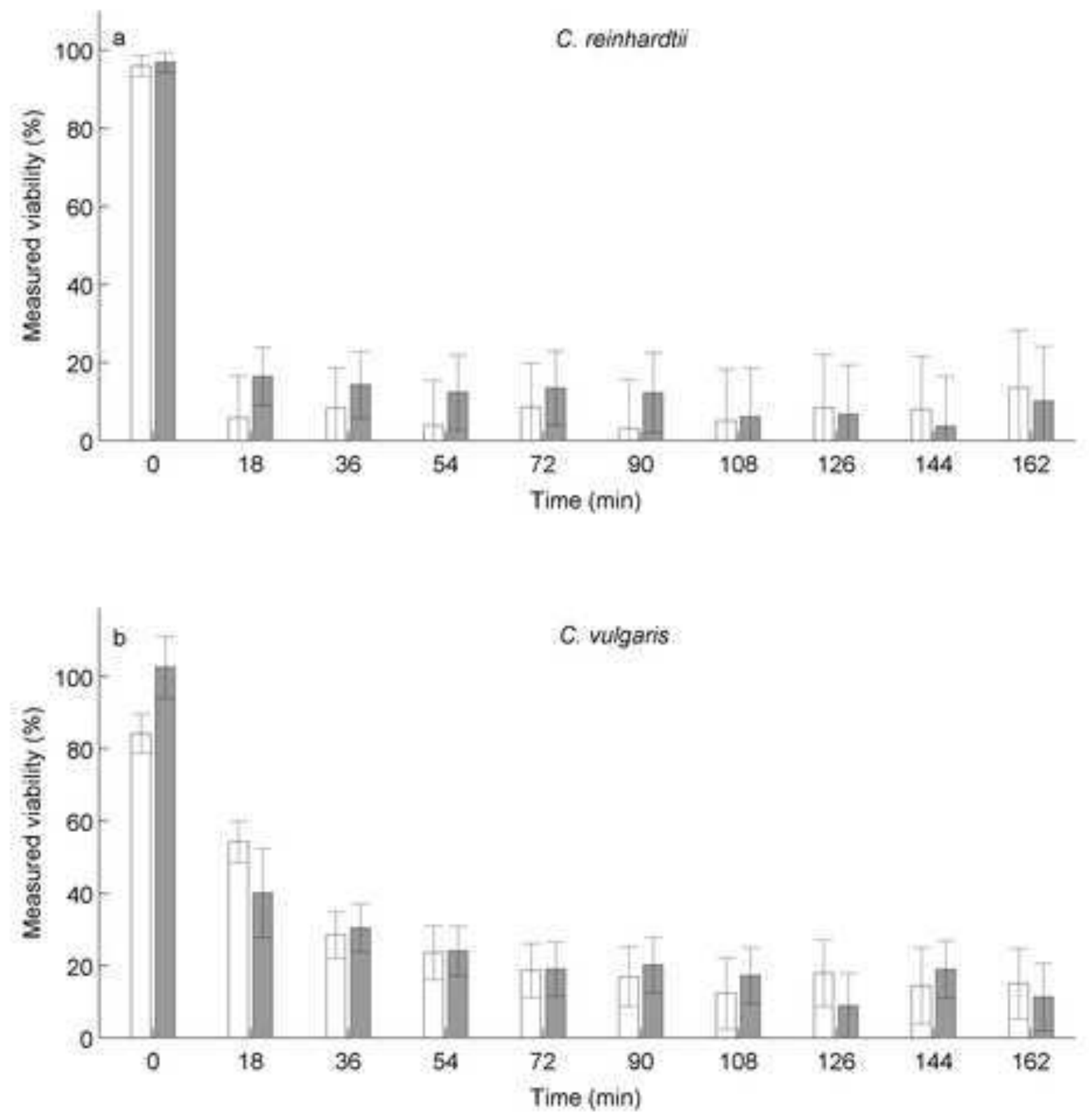


\section{The colorimetric assay of viability for algae (CAVA): a fast and accurate technique - Supplementary information}

Quentin Béchet, Ivan Feurgard, Benoit Guieysse, Filipa Lopes

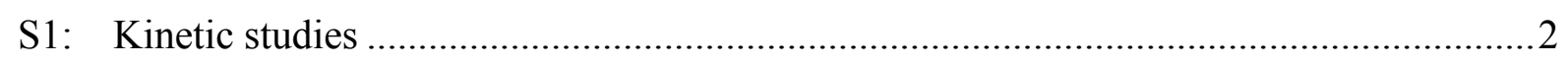

S2: Estimation of confidence intervals using Monte-Carlo simulations .................................

S3: Influence of the algal concentration on the uncertainty on viability ...............................

S4: Impact of the uncertainty on $K$ on the viability results.................................................. 10 


\section{S1: Kinetic studies}

\subsection{Impact of heating time on the amount of erythrosine adsorbed by killed algae}

A sample of Chlorella vulgaris was heated for different periods of time at $60^{\circ} \mathrm{C}$. The cells were then exposed to erythrosine for 10 minutes (initial concentration of $0.04 \mathrm{~g} \mathrm{~L}^{-1}$ ) and the amount of erythrosine adsorbed by the cells was determined by colorimetry as described in the main manuscript. Figure S1-1 shows that the amount of erythrosine adsorbed by $C$. vulgaris cells stabilized after approximately 20 minutes of heating (The fact that $5 \%$ of erythrosine was adsorbed at $\mathrm{t}=0$ indicates that the sample tested was not entirely viable before the heating). For this reason, the Killed sample in the CAVA test was heated for 25 minutes.

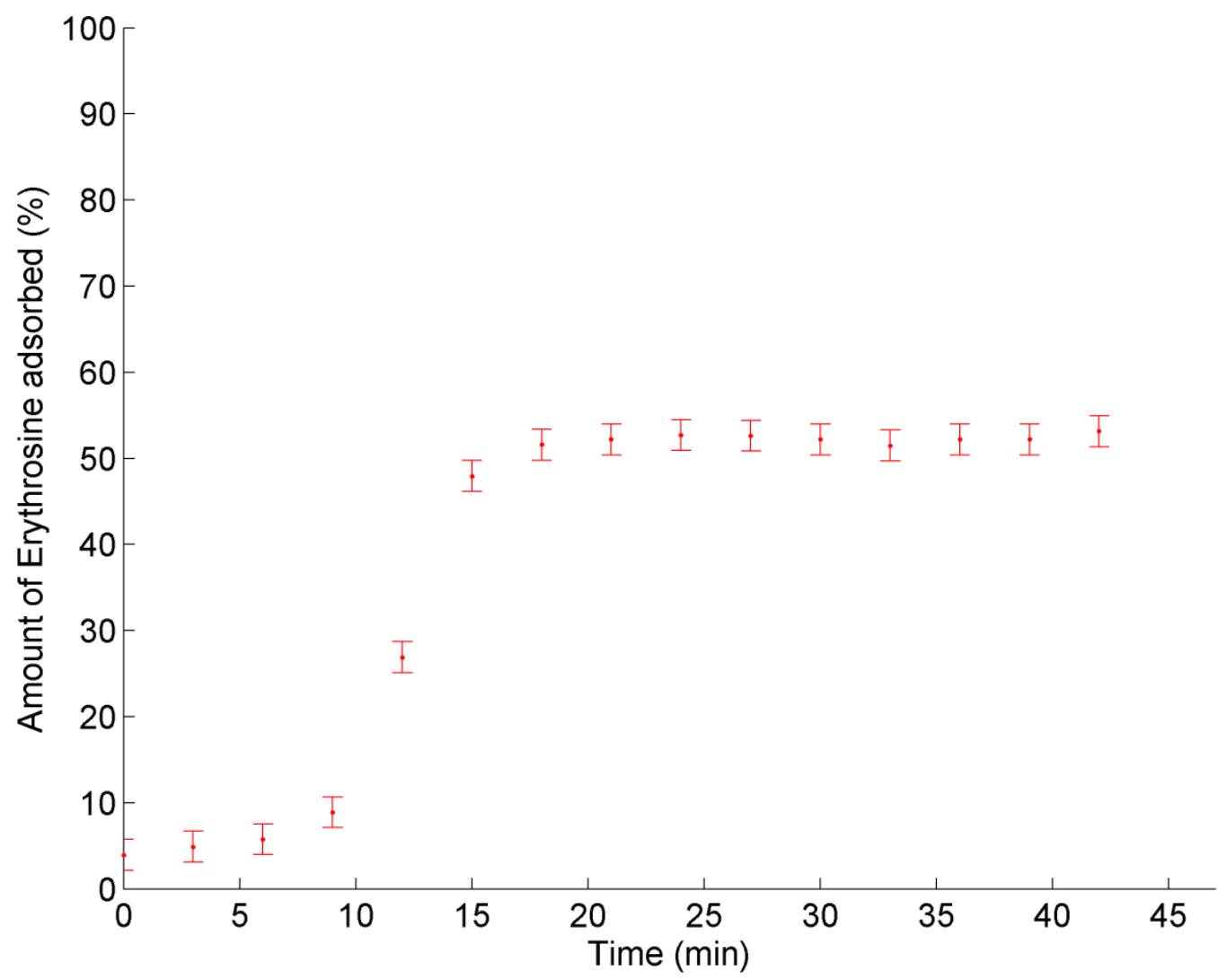

Figure S1-1: Evolution of the amount of erythrosine adsorbed by a $C$. vulgaris sample with the time of heating at $60^{\circ} \mathrm{C}$. The error bars represent the confidence interval at $95 \%$ calculated through Monte-Carlo simulations as discussed in S2. 


\subsection{Kinetic of erythrosine adsorption by killed cells}

Killed samples of $C$. vulgaris were exposed to erythrosine (initial concentration $0.04 \mathrm{~g} \mathrm{~L}^{-1}$ ) for different periods of time. In parallel, a non-killed sample originating from the same algae sample was exposed to the same dose of erythrosine. The amount of erythrosine adsorbed by the samples was estimated by following the protocol described in the main manuscript. Figure S1-2 shows that the equilibrium between the solution and the algae was reached within less than 5 minutes exposure to erythrosine. In addition, as the amount of erythrosine adsorbed by the non-heated cells was constant over time, this indicates that erythrosine was not degraded through a chemical reaction or a biological mechanism, confirming then the Assumption 4 of the CAVA test presented in the main manuscript.
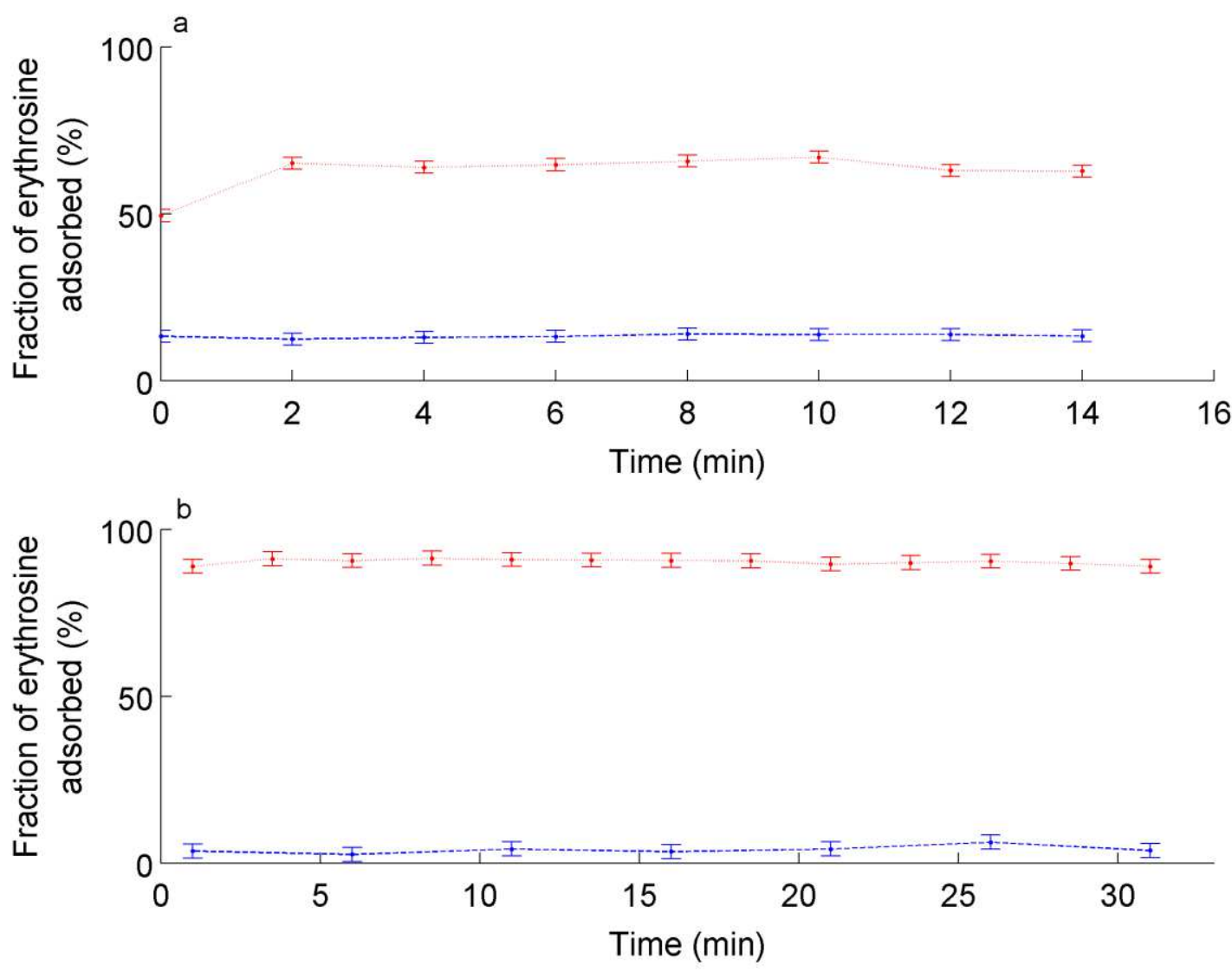

Figure S1-2: Evolution of the fraction of erythrosine adsorbed by $C$. vulgaris samples exposed to $70^{\circ} \mathrm{C}$ for 25 minutes (a) and to $95^{\circ} \mathrm{C}$ for 10 minutes (b). Red point line: killed sample; blue dashed-line: non-killed sample. The error bars represent the $95 \%$ confidence interval estimated using Monte-Carlo simulations as described in S2. 


\section{S2: Estimation of confidence intervals using Monte-Carlo simulations}

\subsection{Introduction}

All the measurements of optical densities for the Sample and the Killed sample $\left(O D_{S}\right.$ and $\left.O D_{K}\right)$ in the protocol of the CAVA test described in the main manuscript were made in duplicates, representing a total of 684 duplicates. The objective of this supplementary information is to explain how these duplicate measurements were used in a statistical analysis to estimate a confidence interval on the viability measurements.

\subsection{Uncertainty on the optical density measurements}

Figure S2-1 shows that the difference between two OD duplicates is not clearly correlated to the concentration of erythrosine in the cuvette (represented by the average OD). As a result, the difference between duplicates is likely to be due to factors other than the algal concentration such as pipetting errors or defaults of the cuvette (scratch, dust, etc.)

By assuming that the error on an OD measurement follows a normal distribution centered on 0 and characterized by a standard deviation $\sigma$, the difference between two duplicates should follow a normal distribution also centered on 0 but characterized by a standard deviation $\sqrt{ } 2 \sigma$. Consequently, the absolute value of this difference follows the half-normal distribution, represented by the following probability density function (Bland, 2005):

$$
\begin{aligned}
& f(x)=\frac{1}{\sigma \sqrt{\pi}} \exp \left(-\frac{x^{2}}{4 \sigma^{2}}\right) \text { for } x \geq 0(\mathrm{~S} 2-1 \mathrm{a}) \\
& f(x)=0 \text { for } x<0(\mathrm{~S} 2-1 \mathrm{~b})
\end{aligned}
$$




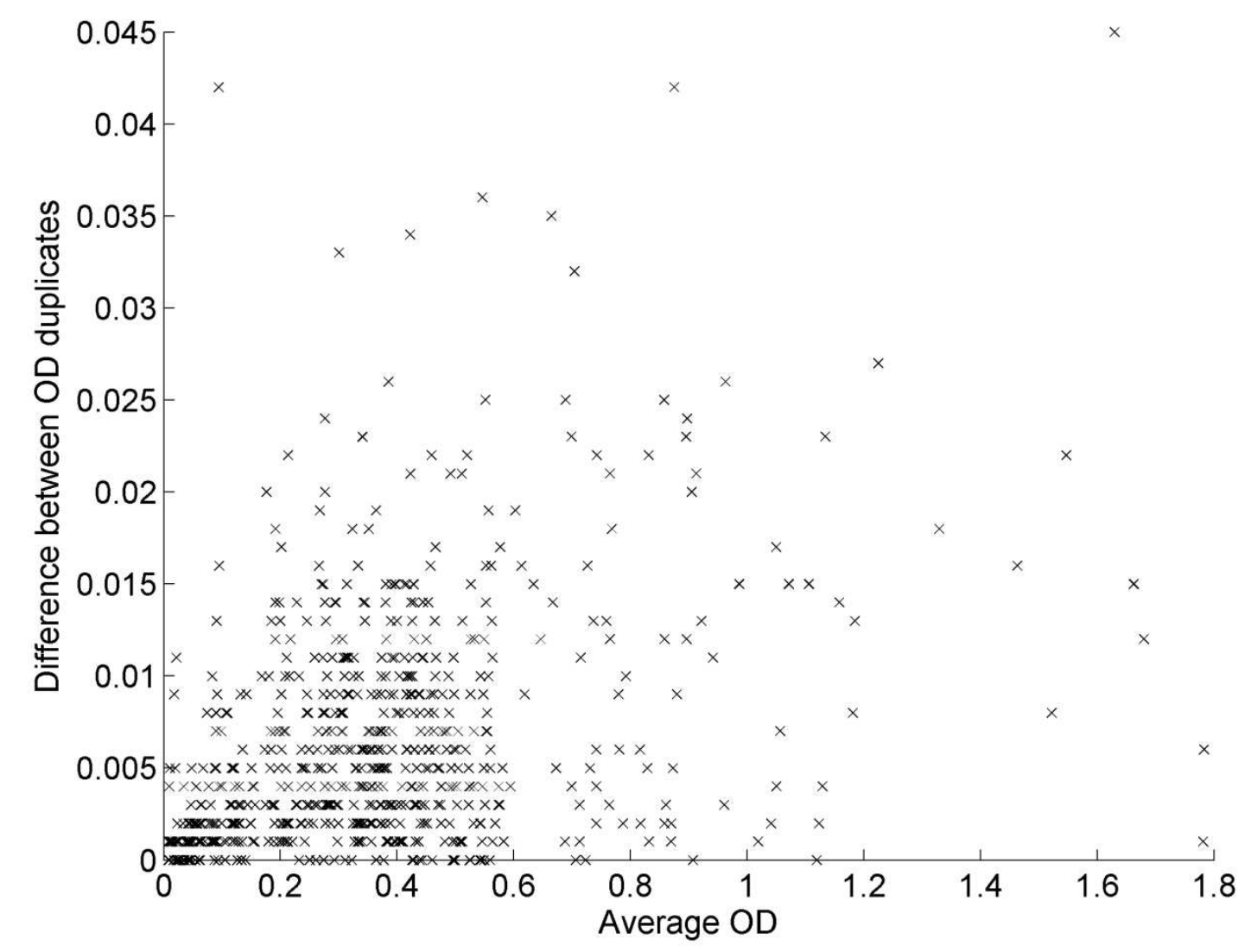

Figure S2-1: Difference between two OD duplicates as a function of the average OD in the cuvette.

Figure S2-2 shows that the absolute value of the difference between OD duplicates indeed follows a half-normal distribution. As demonstrated by Bland (2005), the expectation of a variable $X$ obeying a half-normal distribution is:

$E(X)=\frac{2}{\pi} \sigma(\mathrm{S} 2-2)$

The standard deviation $\sigma$ can therefore be estimated as follows:

$\sigma=\frac{\pi}{2} \bar{X}(\mathrm{~S} 2-3)$

Numerically, the standard deviation was found to be $5.77 \times 10^{-3}$. 


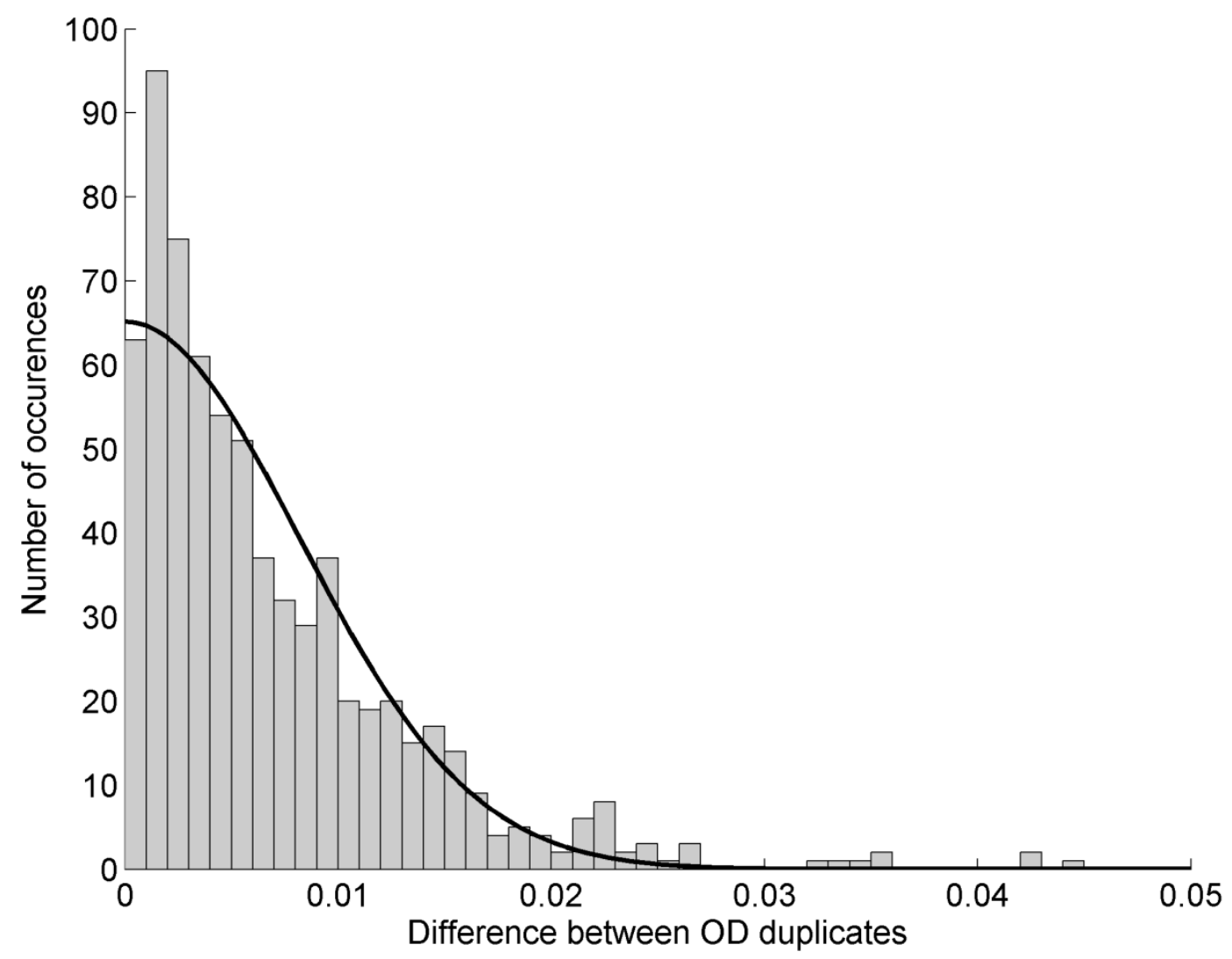

Figure S2-2: Distribution of the difference between OD duplicates and fitting (plain line) to the half-normal distribution described by Equations S2-1a and S2-1b (with $\sigma=5.77 \times 10^{-3}$ ).

\subsection{Calculation of the confidence interval on OD measurements}

As OD measurements were made in duplicates, the OD values used in the formula of the viability (Equation 10 in the main manuscript) were the average ODs, expressed as:

$O D_{a v}=\frac{1}{N_{r}} \sum_{i} O D_{i}(\mathrm{~S} 2-4)$

where $N_{r}$ is the number of replicates of a measurement (e.g. 2 for duplicates) and $O D_{i}$ are the values of these replicates. As shown in the previous section, a sampled value of optical density $O D_{i}$ can be assumed to follow a normal distribution centered on the 'true' value of the $\mathrm{OD}\left(O D_{\text {true }}\right)$ and with a standard deviation $\sigma . O D_{a v}$ can therefore be assumed to follow a normal distribution centered around $O D_{\text {true }}$ and characterized by a standard deviation $\sigma / \sqrt{ } N_{r}$. The confidence interval on an OD measurement at 95\% was therefore expressed as follows: 


$$
O D_{\text {true }} \in\left[O D_{a v}-1.96 \frac{\sigma}{\sqrt{N_{r}}} ; O D_{a v}-1.96 \frac{\sigma}{\sqrt{N_{r}}}\right]
$$

\subsection{Calculation of the confidence interval on the isotherm parameters}

The error on OD measurement during the characterization of the isotherm caused uncertainty on the fitted values of the isotherm parameters. Monte-Carlo simulations were performed in order to quantify the level of accuracy on the parameters $K, q_{m}, K_{f}$, and $n$.

Monte-Carlo simulations consisted on iterating the fitting of the isotherm parameters a large number of times (10,000 in this case). At each iteration, the values of the optical densities for each data point were randomly sampled around the measured value and within the confidence interval given by Equation S2-5. The confidence interval for each isotherm parameter was then calculated from the standard deviation of the 10,000 values generated during the MonteCarlo simulations.

\subsection{Calculation of the confidence interval on viability}

According to Equation 10 in the main manuscript, there are two sources of uncertainty in the expression of the viability: the experimental error on the optical densities and the value of the parameter $K^{\prime}$. The level of confidence on the optical densities was determined from Equation S2-5. The confidence interval on the parameter $K$ ' was taken equal to the confidence interval on $K$ determined in section 2.4 multiplied by the constant $\alpha$ (see the main Manuscript for details).

For each viability measurement, Monte-Carlo simulations consisted on repeating the calculation of the viability by using randomly generated values for the different ODs and the parameter $K^{\prime}$ in Equation 10. The level of confidence on the measured viability was then calculated from the standard deviation of the multiple resulting viability values (here 10,000 values) obtained at each iteration. 


\section{References}

Bland, J.M. 2005. The half-normal distribution method for measurement error: two case studies. Un-published talk available on http://www-users.york.ac.uk/ mb55/talks/halfnor.pdf). 


\section{S3: Influence of the algal concentration on the uncertainty on viability}

Figure S3-1 shows that the level of accuracy on the estimated viability on a half-dead algal sample significantly decreases when the algal concentration decreases.

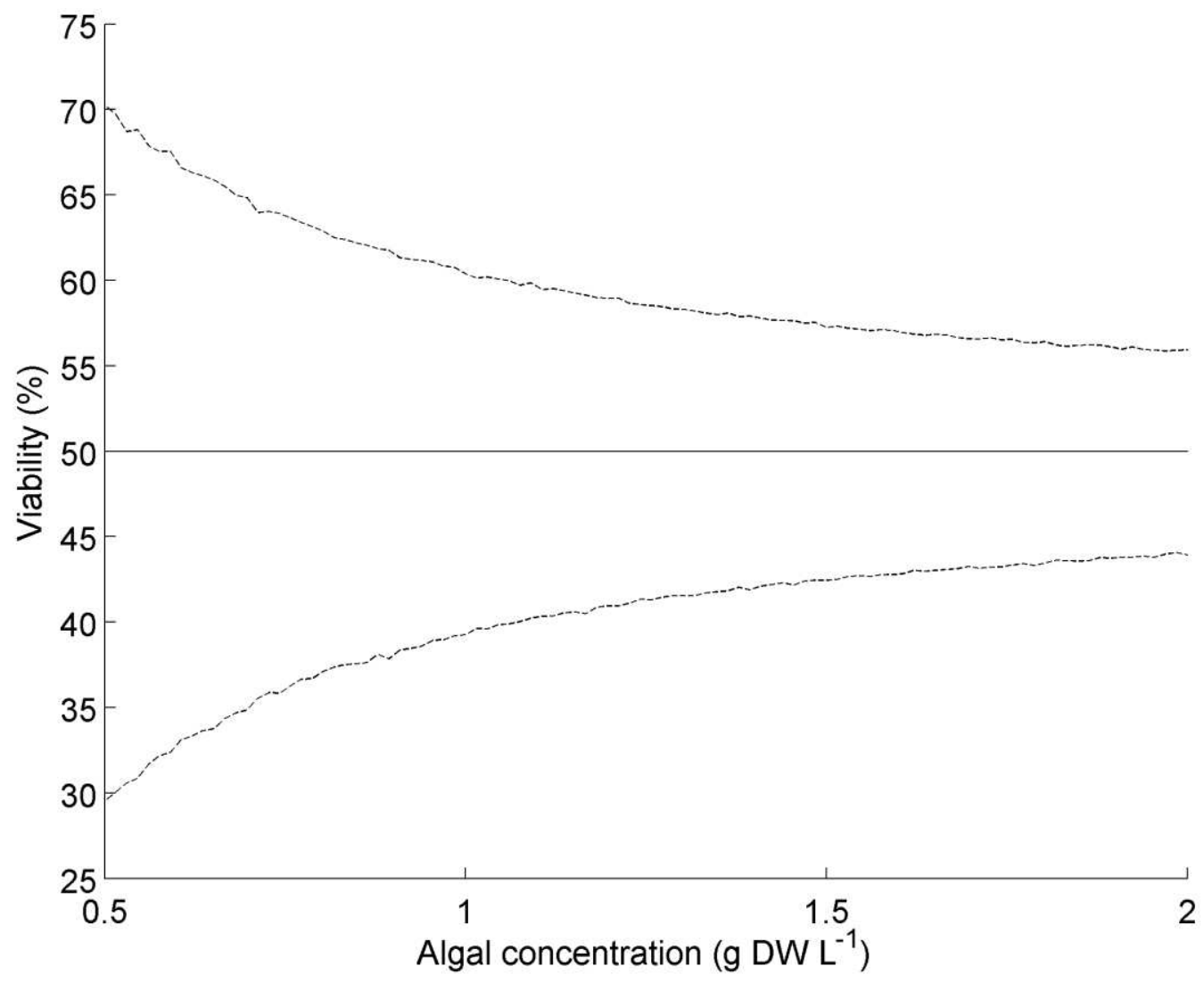

Figure S3-1: Measured viability (plain line) and associated confidence interval at 95\% (dashed-line) of a hypothetical 50\%-viable C. vulgaris sample for different algal concentrations (assuming that $O D_{S}$ and $O D_{K}$ are measured in duplicates and $O D_{B}$ in triplicate). The algal concentrations represented on the $\mathrm{x}$-axis is the concentration in the 0.6 $\mathrm{mL}$ added in the Sample and the Killed sample tubes. The error bars represent 95\% confidence intervals estimated through Monte-Carlo simulations. 


\section{S4: Impact of the uncertainty on $K$ on the viability results}

As shown by Equation 10 in the main manuscript, estimating the viability of an algal sample requires determining the value of the half-saturation constant $K$. In this study, this parameter was assumed to be constant despite the potential changes of algal adsorption properties due to physiological changes (e.g. change of cell size, cell wall composition, etc.). This section investigates how the variability of this parameter can influence the results of the CAVA test.

In a hypothetical case, let us consider a 50\% viable $C$. vulgaris sample. Figure S4-1 shows the viability of the sample estimated with a coefficient $K$ of $0.0378 \mathrm{~g} \mathrm{~L}^{-1}$ as shown in Table 1 if the true value of $K$ varies from 0.0189 (50\%) to 0.0756 (200\%). As shown by Figure S4-1, such a large variability in the value of $K$ does not significantly affect the estimated viability. As a result, $K$ can be assumed to be constant without significant loss of accuracy in viability.

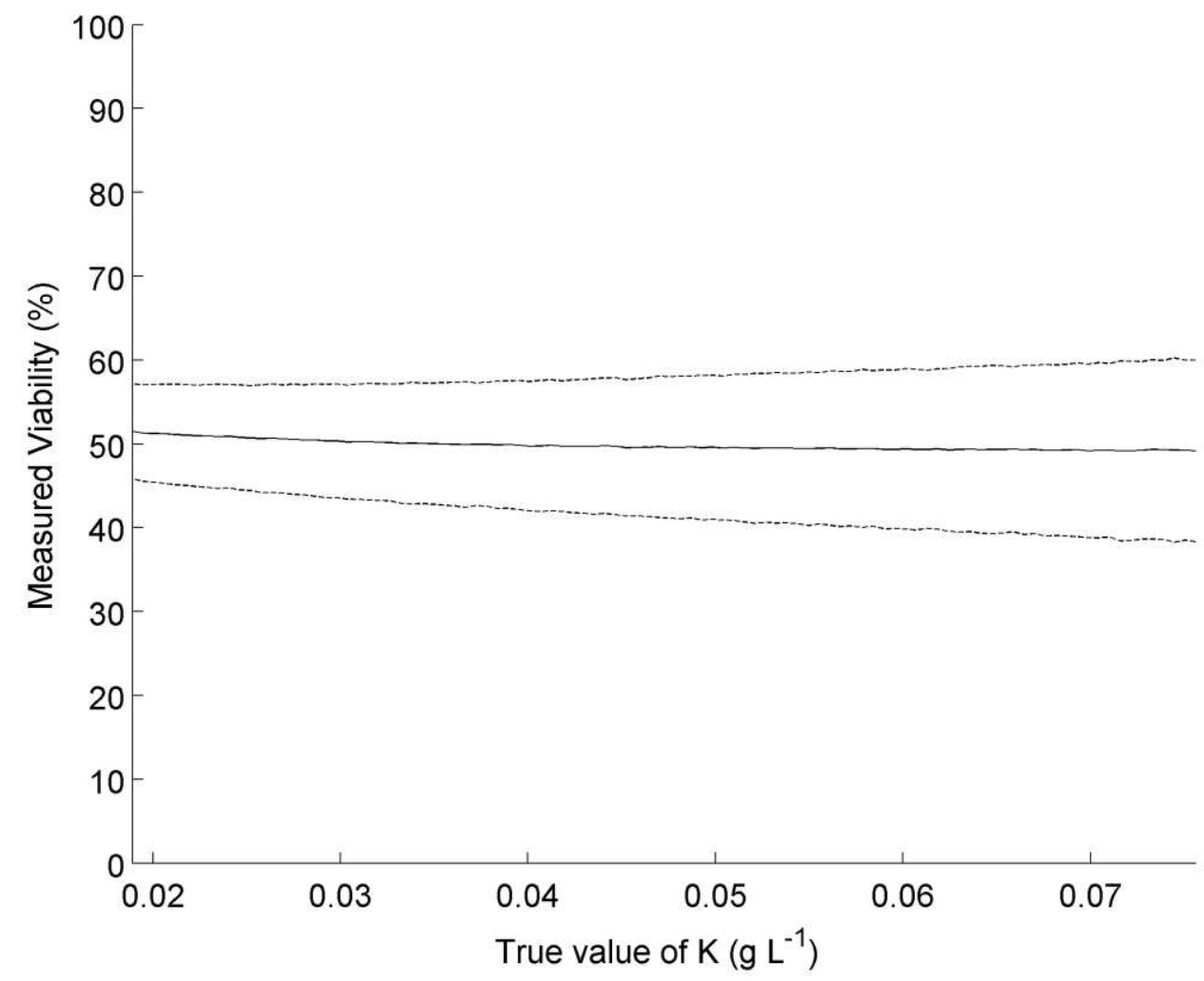

Figure S4-1: Viability of a 50\% viable $C$. vulgaris sample estimated with $K=0.0378 \mathrm{~g} \mathrm{~L}^{-1}$ for different true $K$ values (Hypothetical case: $X=1 \mathrm{~g} \mathrm{DW} \mathrm{L}^{-1}$ ). Plain line: Estimated viability; dashed-line: confidence interval at $95 \%$. 